\title{
Nilotinib Regimen
}

National Cancer Institute

\section{Source}

National Cancer Institute. Nilotinib Regimen. NCI Thesaurus. Code C160091.

A chemotherapy regimen consisting of nilotinib that may be used in the treatment of gastrointestinal stromal tumors (GISTs) and chronic myeloid leukemia (CML). 